\title{
Accidental gastrocolonic anastomosis by apposition stent: a one-month healing delay makes it possible to treat a stabilized gastrocolonic fistula rather than a double perforation
}

Misplacement of self-expandable apposition stent in the colon during endoscopic ultrasound (EUS) transgastric drainage of a post-pancreatitis necrotic collection is a rare adverse event [1] leading to a double perforation (stomach and colon) if the stent is removed immediately. Therefore, we proposed a waiting strategy to transform gastrocolonic anastomosis into a gastrocolonic fistula.

éWe report the case of a 76-year-old man admitted for acute necrotizing pancreatitis in a general hospital in our area.
During an attempt of transgastric drainage for a necrotic collection, the colon was accidentally targeted and the apposition stent deployed (Hot AXIOS; Boston Scientific, Marlborough, Massachusetts, USA), creating a gastrocolonic anastomosis. After discussion, we recommended leaving the stent in place for 1 month instead of dealing with two perforations (colon and stomach). After 4 weeks, the patient was referred to our center. To repair the communication, simultaneous upper and lower endoscopies were performed with two scopes ( $\mathbf{F i g . 1}$ $\checkmark$ Video 1) to treat the two perforations in case the gastrocolonic attachment failed. The colonoscopy showed severe left colitis induced by gastric acid. The stent was removed using the upper gastrointestinal (GI) access and we confirmed the attachment of the stomach and colon through a stabilized fistula without any leakage.

éTo close the fistula, we combined circumferential endoscopic submucosal dissection (ESD) of the surrounding mu-
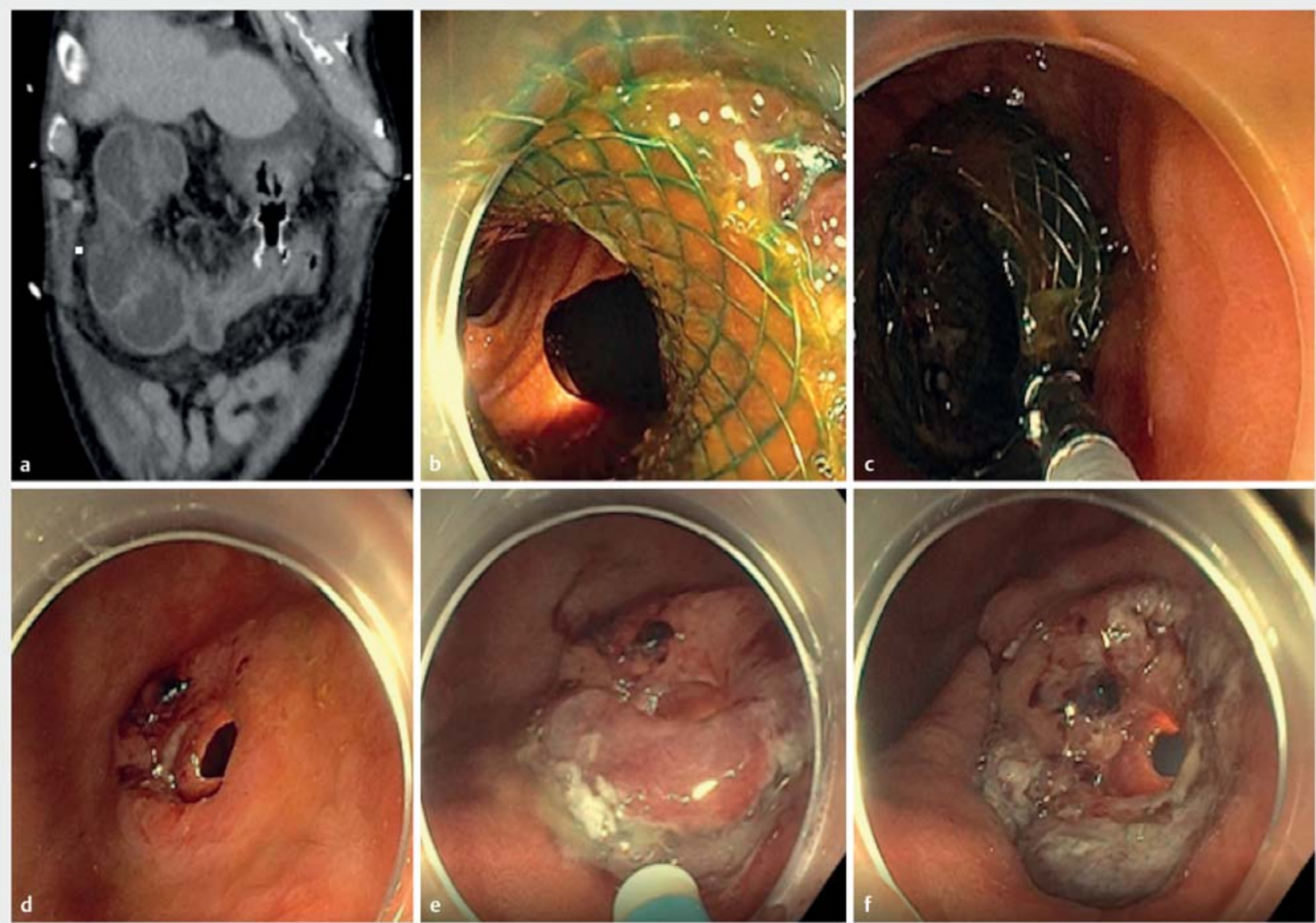

- Fig. 1 Closure procedure for the fistula. a Computed tomography scan aspect of the gastrocolonic anastomosis. $\mathbf{b}$ Endoscopic aspect of the gastrocolonic anastomosis. c Stent removal. d Aspect of the stabilized fistula with gastrocolonic attachment. e Endoscopic submucosal dissection of the surrounding mucosa. $\mathbf{f}$ Aspect of the fistula tract after dissection of the surrounding mucosa. 


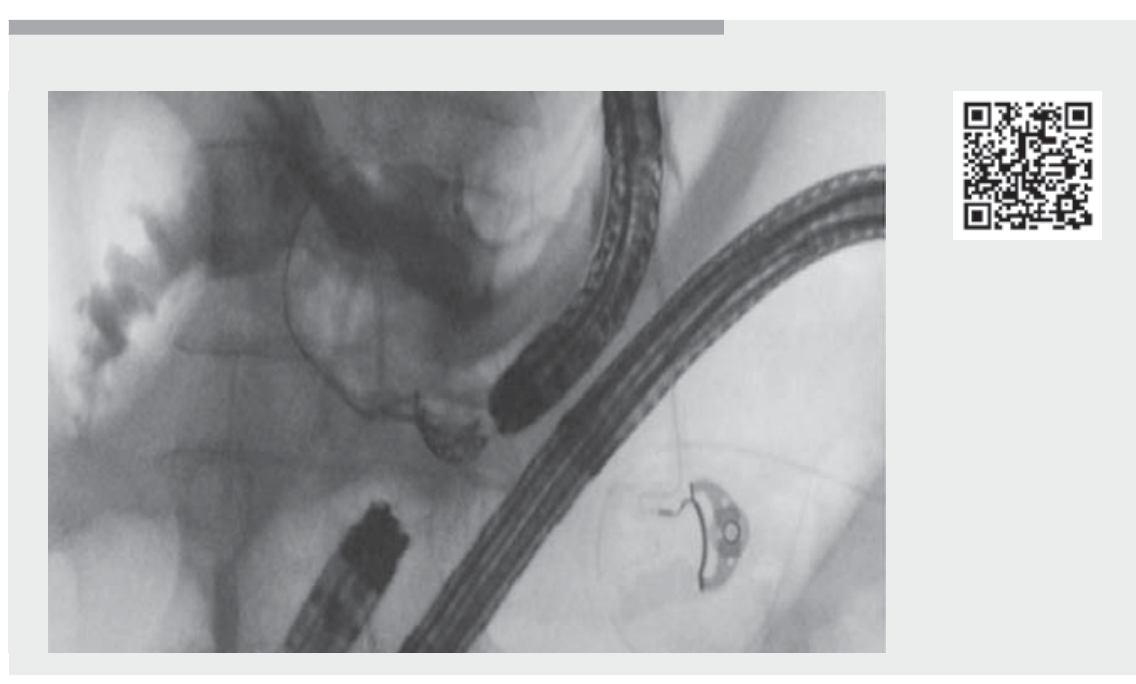

$\checkmark$ Video 1 Endoscopic closure of the gastrocolonic fistula stabilized by a 1-month healing period.
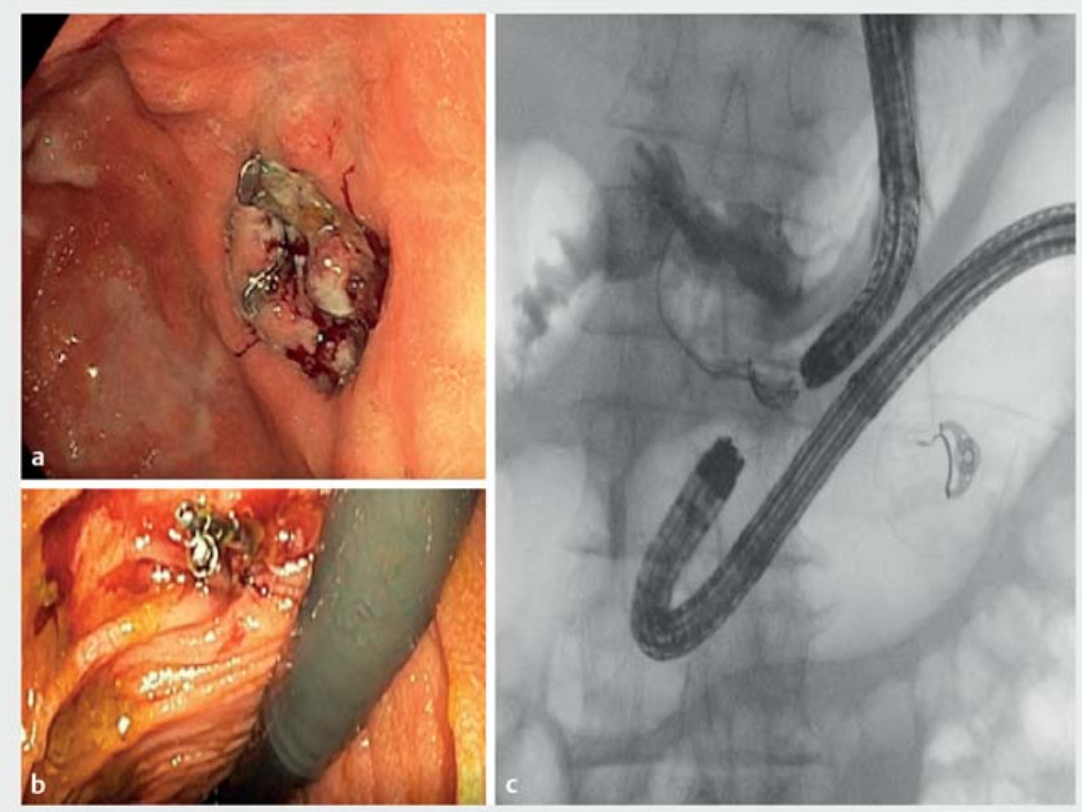

Fig. 2 Aspect of the closure. a Gastric aspect with the over-the-scope clip in place. b Colon aspect with two additional hemoclips. c X-ray aspect confirming the lack of leakage.

cosa and over-the-scope clipping of the fistula tract as previously reported (-Fig.2) [2-4]. Two hemoclips were additionally placed on the colonic side. Successful closure without leakage was confirmed radiologically with contrast in order to facilitate endoscopic closure [5]. Combining endoscopic submucosal dissection of the surrounding mucosa and over-the-scope clipping is effective to treat digestive fistulas.

Endoscopy_UCTN_Code_CPL_1AH_2AG

\section{Competing interests}

The authors declare that they have no conflict of interest.

The authors

Alexia Laroyenne ${ }^{1}$, Pierre Lafeuille ${ }^{1}$, Thomas Lambin ${ }^{1}$, Timothée Wallenhorst ${ }^{2}$, Benjamin Hamel $^{3}$, Jérôme Rivory ${ }^{1}$, Mathieu Pioche ${ }^{1}$

1 Department of Endoscopy and HepatoGastroenterology, Pavillon L, Edouard Herriot Hospital, Lyon, France

2 Department of Endoscopy and HepatoGastroenterology, Pontchaillou University Hospital, Rennes, France

3 Department of Endoscopy and HepatoGastroenterology, Nord West Hospital, Villefranche-sur-Saône, France

\section{Corresponding author}

\section{Mathieu Pioche, MD}

Endoscopy Unit, Digestive Disease Department, Pavillon L, Edouard Herriot Hospital, 69437 Lyon Cédex, France mathieu.pioche@chu-lyon.fr

\section{References}

[1] Rana SS, Shah J, Kang M et al. Complications of endoscopic ultrasound-guided transmural drainage of pancreatic fluid collections and their management. Ann Gastroenterol 2019; 32: 441-450. doi:10.20524| aog. 2019.0404

[2] Ciochina M, Cruceru M, Rivory J et al. Esophagobronchial fistula after sleeve gastrectomy successfully treated by endoscopic submucosal dissection and over-the-scope clip. Endoscopy 2019. doi:10.1055/a-10114092

[3] Bertrand G, Jacques ], Rivory J et al. Deep endoscopic submucosal dissection of a re- 
fractory tracheoesophageal fistula using clip-and-line traction: a successful closure. Endoscopy 2017; 49: 1278-1280. doi:10.1055/s-0043-119348

[4] Wallenhorst T, Jacques J, Bouguen G et al. Successful closure of a rectal fistula of Crohn's disease using endoscopic submucosal dissection combined with an over-thescope clip. Am J Gastroenterol 2019. doi:10.14309/ajg.0000000000000366

[5] Keane MG, Barbouti O, Reffitt D et al. Removal of a migrated lumen-apposing metal stent and endoscopic closure of a gastrocolonic fistula. Endoscopy 2020; 52: E170E171. doi:10.1055/a-1011-3869

\section{Bibliography}

Endoscopy 2022; 54: E212-E214

DOI 10.1055/a-1488-5872

ISSN 0013-726X

published online 12.5.2021

(C) 2021. Thieme. All rights reserved.

Georg Thieme Verlag KG, Rüdigerstraße 14,

70469 Stuttgart, Germany

\section{ENDOSCOPY E-VIDEOS}

https://eref.thieme.de/e-videos

口回 Endoscopy E-Videos is an open access online section, 回躲: reporting on interesting cases and new techniques in gastroenterological endoscopy. All papers include a high quality video and all contributions are freely accessible online. Processing charges apply (currently EUR 375), discounts and wavers acc. to HINARI are available.

This section has its own submission website at

https://mc.manuscriptcentral.com/e-videos 